\title{
Anatomic reconstruction of chronic symptomatic anterolateral proximal tibiofibular joint instability
}

\author{
Reply to the comments by Michel van den Bekerom
}

\author{
Robert F. LaPrade $\cdot$ Patrick K. Horst
}

Received: 10 February 2011/Accepted: 22 March 2011/Published online: 30 April 2011

(C) Springer-Verlag 2011

\section{Dear Editors,}

Thank you for your thoughtful comments regarding our manuscript on an anatomic reconstruction of chronic symptomatic anterolateral proximal tibiofibular joint instability [1]. As we noted, the goal of an anatomic reconstruction in our report was to allow our patients a full return to athletics and alleviation of symptoms. At two years postoperatively, we achieved this goal. We have since gone on to use this reconstruction in several more patients and have found it to be effective for treatment.

Treatment options such as fibular head resection, proximal tibiofibular joint arthrodesis, or temporary fixation of the fibular head with screw fixation have all been previously reported. However, none have been proven to restore stability in active individuals.

We respectfully disagree that this is an extensive surgical option because in our hands it only takes about 20 min.

Fibular head resection and joint arthrodesis are contraindicated in children and athletes, and temporary screw fixation can be complicated by screw breakage [2].

To our knowledge, it has not been reported in the literature if temporary screw fixation allows for a return to athletics while minimizing complications. We also respectfully disagree that for a patient with chronic

\section{R. F. LaPrade $(\square)$}

Director Steadman Philippon Research Institute Biomechanics Research Laboratory, Vail Colorado Complex Knee Surgeon, The Steadman Clinic, Vail Colorado, 181 W. Meadow Drive, Suite 400, Vail, CO 81657, USA

e-mail: rlaprade@steadmanclinic.net

\section{P. K. Horst}

Department of Orthopaedic Surgery, UCSF, 500 Parnassus Avenue, MU 320, Box 0728, San Francisco, CA 94143, USA anterolateral symptomatic subluxation of the proximal tibiofibular joint that further physical therapy, after three months, would be indicated. While properly treated, patients with an acute injury almost always heal; once a patient has a chronic subluxation, we believe further stabilization would be indicated at that point.

We also concur this is a rare problem. We are a referral center for complex pathology around the posterolateral corner of the knee and have a small series of patients. However, we do believe this anatomic reconstruction is a simple and effective means to treat this pathology without the need for nonanatomic treatment or hardware fixation.

Thank you once again for your kind comments regarding our manuscript.

\section{References}

1. Horst PK, LaPrade RF (2010) Anatomic reconstruction of chronic symptomatic anterolateral proximal tibiofibular joint instability. Knee Surg Sports Traumatol Arthrosc 18:1452-1455

2. Van den Bekerom MP, Weir A, van der Flier RE (2004) Surgical stabilization of the proximal tibiofibular joint using temporary fixation: a technical note. Acta Orthop Belg 70:604-608 